\title{
The Future of Industrial Marketing Management
}

Adam Lindgreen, Copenhagen Business School and University of Pretoria's Gordon Institute of Business Science ${ }^{1}$

C. Anthony Di Benedetto, Fox School of Business, Temple University ${ }^{2}$

Being named the new Editors-in-Chief of Industrial Marketing Management (IMM) was both an honor and an exciting challenge for us, as we look to help develop and enhance the reputation, standing, and impact of IMM. In taking over the Editorship from Peter LaPlaca, we also acknowledge his sterling contributions to the successful development of IMM and thank him for his dedication to the journal's position.

We are taking over a journal in good health. IMM is published by Elsevier, the largest journal publisher in the world. As such, IMM enjoys the support of a very innovative publisher, a publisher that has invested millions of dollars in its systems to better convey the knowledge developed by academic researchers. IMM steadily has advanced in quality and its impact on marketing theory and practice. It is currently the highest rated journal focusing exclusively on business-to-business (B2B) marketing management and, according to its Google statistics, is the fourth ranked marketing journal overall.

The inaugural issue of IMM appeared in September 1971, for which R. Derek Medford served as the first editor-in-chief. Prior to then, no single journal had been dedicated specifically to academic research in the growing area of business-to-business marketing. In Peter LaPlaca's first year of editorship (1994), IMM published four issues, containing 41 articles and 365 pages. By 2002, the number of issues per year had doubled to eight. By Peter LaPlaca's last year as co-editor-in-chief (2016), IMM published more than triple the number of articles and total pages. Since 2014, more than 130 articles and 1,400 pages have been published yearly. Thus, in 2014, 132 articles appeared, totaling 1,556 pages. The submission count peaked at 981 manuscripts in 2014-a remarkable growth rate of nearly $500 \%$ ! A

\footnotetext{
${ }^{1}$ Adam Lindgreen, Department of Marketing, Copenhagen Business School, Solbjerg Plads 3, 2000 Frederiksberg C, Denmark and University of Pretoria's Gordon Institute of Business Science, 26 Melville Road, Illovo, Johannesburg, South Africa. E-mail: adli.marktg@cbs.dk.

${ }^{2}$ C. Anthony Di Benedetto, Fox School of Business, Alter Hall 523, 1801 Liacouras Walk, Philadelphia, PA 19122-6083, USA.
} 
changeover to the online submission system in 2015 led to a temporary decrease in the number of submissions, but as of 2016, the submission count remained steady at 508 . Throughout this period, the acceptance rate ranged from $13 \%$ to $26 \%$.

Prominently, we aim to work closely with the journal's Advisory Board, made up of outstanding scholars from all around the world. This board will assist us in making important strategic decisions; the members' roles remain fluid, so that they can develop as IMM does. We look forward to sharing ideas with these esteemed colleagues.

As editors-in-chief, we intend to continue to build on the editorial rigor and success of this journal. Even as we honor the history of $I M M$, we commit to moving $I M M$ forward, toward new heights. To do so, we will actively pursue an improved ranking for IMM in international journal rankings. This aim is served better if IMM as a journal embodies a unique position in the minds of scholars. In other words, we want the answer to the question, "Why should I submit my work to IMM?" to be evident, clear, and obvious. Accordingly, we plan to build on Peter LaPlaca's initiatives and introduce several exciting initiatives of our own in the course of the coming year.

\section{Aim and Scope of IMM}

In our view, the goal of scholarly research should be to facilitate and encourage communication between academia and practice. Yet many journals seem to be losing this focus. We explicitly seek to ensure that $I M M$ provides all readers a wealth of robust, highly relevant information and thus serves as a functional bridge between academic theory and practitioner applications, even as it maintains stringent standards for scientific rigor. With its unique attention to industrial and B2B markets, IMM must offer both practical advantages and new impetus for marketers who seek to enhance their skills and to improve effectiveness and efficiency of such markets. This comprehensive approach will keep readers abreast of the timeliest data and current thinking necessary for better marketing decisions and strategy in global industrial and B2B markets.

Moreover, we strongly encourage novel, groundbreaking contributions from disparate research and B2B marketing management traditions, as well as cross-fertilization with external disciplines, because such efforts can produce innovative ideas, new conceptual developments, and clever research methodologies. In a similar vein, we actively encourage global contributions from scholars representing various B2B marketing management domains. Our criteria for reviewing submitted manuscripts require that they be based on high quality, rigorous scholarly research; we expressly note here that we have no bias or preference for 
empirical work versus theory, and we welcome diverse methodological, philosophical, and theoretical approaches. Our goal is to publish research situated in either a pure or applied research tradition, derived from a stringent theoretical conceptualization, which exhibits an appropriate, defensible research methodology.

$I M M$ therefore will continue to look for world-class research focusing on $\mathrm{B} 2 \mathrm{~B}$ marketing management, and we will continue to move from descriptive research (such as single case studies) to more explanatory and predictive research. We will continue to put more emphasis on articles employing pluralistic research methodologies, especially those articles that adapt research methodologies from other disciplines to explain industrial marketing management behavior, as well as research focused on improving the effectiveness and efficiency of B2B marketing management practitioners. We will welcome methodological entries that adjust designs applied in prior studies or modify extant experimental procedures to enhance the validity of statistical outcomes or increase experimental realism.

We also seek more manuscripts that reflect the following three notable research areas. First, literature reviews that offer helpful surveys of critical concepts in current marketing thought. By describing, summarizing, and critically evaluating previous work, good literature reviews will make significant contributions to our understanding of the overall topic, as well as provide integrative framework(s) and suggestions for further research. Second, conceptual studies that improve existing definitions of original constructs, offer better theoretical rationales for existing linkages, identify new constructs that should be included in existing conceptual frameworks, or reveal theoretical linkages and their accompanying rationale to suggest more comprehensive integrative frameworks related to a topic. Third, empirical studies that address the practical issues associated with, for example, designing, developing, implementing, and monitoring a customer relationship management program, such that they include multiple hierarchical levels and departments within an organization. Manuscripts that effectively represent any of these three areas serve to enhance and expand B2B marketing management knowledge, and $I M M$ will be receptive to such manuscripts.

Also, IMM will be open to new and even risky views on novel theory development. In detail, we are warmly receptive to articles that cover controversial topics, new and maybe radical ideas, developments that challenge existing theories and paradigms, and efforts to develop and test of new theories. We should remember that when 'interactionism' and especially 'networks' views were first introduced, it took several years before they reached a 'legitimized' level (and enabled explanatory and predictive research). Complex and open systems are notoriously difficult to explain. So we would like to embrace, for example, the 
forthcoming theorizing on 'complex ecosystems' at the descriptive level (first), then followed by more explanatory and predictive studies. Novelty and controversy for their own sake, however, are insufficient; we hold all manuscripts to the same standards for valuable contributions to marketing discourse.

Moreover, we welcome manuscripts that fall generally into the broad category of replication studies, as long as they meet the high quality standards of $I M M$ and offer significant contributions, rather than simply repeating well-known findings in different cultures. Such replications offer important benefits for advancing marketing thought, by moving mere 'knowledge claims' toward outcomes that more confidently might be called 'knowledge'.

\section{Topics}

Which research trends impact industrial and $\mathrm{B} 2 \mathrm{~B}$ marketing management theory and practice? In the past few years, research has broadened to focus on topics such as "innovation networks and their management," "the role of management cognitions and activities in making sense and orchestrating networks," and "better understanding of the dynamics of the network development" involving process and longitudinal case research, addressing the management of business and innovation networks. IMM will continue to publish this kind of research.

Clearly, any discipline needs innovation to stay fresh. These new developments need not only be in theory, but can also encompass innovative research methodologies. Thus, we are in for a period of consolidation where we test and confirm/refute the theoretical developments that have been made in the past. In terms of methodological developments, there are new developments, for example, in latent growth curve modelling for the quant jocks, in applying fuzzy set Qualitative Comparative Analysis, or in expanding what we know about using network pictures as a research tool for the qualitative people. IMM will continue to publish research using new research methodologies applied to industrial marketing, as well as new theories of how business markets work.

There are two large research perspectives that dominate industrial and $\mathrm{B} 2 \mathrm{~B}$ marketing management research. Much of the research in North America applies a functionalist use of quantitative methods focused on observable phenomena. In contrast, the IMP group, which is prevalent in Europe, uses an interpretivist approach preferring qualitative methods that explore meanings from different human perspectives. Both of these approaches produce excellent research that broadens our understanding of industrial and B2B marketing 
management and advances the science and practice industrial marketing. $I M M$ will continue to publish both functionalist and interpretivist research.

Finally, we need more globally focused research on business relationships. IMM will publish research that helps understand how mutually beneficial relationships develop and thrive among business organizations across the world. It will also publish research that helps improve the efficiency of global B2B exchanges and the effectiveness of industrial marketing managers.

In an editorial later this year, we will identify and discuss in more detail some of the topics that we believe will advance knowledge on improving $\mathrm{B} 2 \mathrm{~B}$ marketing management understanding and applications.

\section{Editorial Process and Reviewers}

The editors (or guest editors) initially will review submitted manuscripts to determine whether a manuscript satisfies the journal's editorial guidelines, provides meaningful implications for B2B marketing management, and has the potential to invoke constructive reviews. Manuscripts that meet these threshold standards will be forwarded to three reviewers. Those manuscripts that do not will be rejected; so, too, will manuscripts that have not been prepared using IMM's formatting guidelines (cf. website). We consider it more helpful for authors to receive quick feedback about their work if it is unlikely to be consistent with the ethos of $I M M$ than to spend time in a review process with minimal chance of success. This approach also offers the added benefit of giving these authors a ready opportunity to submit their work to more receptive outlets instead.

$I M M$ has grown in many ways over the last decade: more submissions each year, more rejections, more articles published, more pages each year, better quality articles being published, more citations, and an increasing impact factor and reputation. The great bulk of the effort to achieve this quality growth has come from the more than 400 people who donate their time and talent to serve as reviewers for this journal. However, what does it mean to be a reviewer, especially for a top journal?

Yes, reviewers do evaluate submitted manuscripts and recommend acceptance, rejection, or revision. Revised manuscripts are then re-reviewed at least once and often two, three, or even four times. More important than recommendations, though, are the critical comments to the authors. Good reviewers take this responsibility very seriously. Despite their own teaching and research obligations, IMM reviewers take significant time to provide authors with constructive critiques on their submissions, even for manuscripts they recommend be rejected. 
It is quite common that three reviewers each will send in three-to-five pages of comments, and when we as editors put this all together for the authors, the resulting letter can be eight-totwelve pages of feedback. Reviewers also provide suggestions for additional research that would improve the manuscript, or provide additional references that the authors did not include in the manuscript. Reviewers suggest improvements to tables and figures to better convey information to readers. Reviewers even make recommendations to improve the manuscript's title.

A journal's reputation and ranking partly are determined by whether or not reviewers render their recommendations and constructive criticism in a timely fashion. We therefore ask that all reviews be completed in four-to-six weeks from the time they are sent to the reviewers. Most reviewers do meet this expectation; others do not. To keep authors waiting three or four months or sometimes more is quite unfair and disrespectful to the authors. If reviewers cannot complete their assigned reviews by the requested deadline, whether due to workload or lack of qualifications for the specific manuscript, they should let us (or the guest editors) know as soon as possible. We find it particularly upsetting when reviewers, who are persistently tardy with their reviews, complain when reviews of their own submitted manuscripts are a week or two past the suggested date. As their research focus changes, reviewers should voluntarily resign for review boards that no longer represent their research interest.

This is what specifically reviewers are doing. Their first responsibility is to evaluate whether each manuscript makes a substantial contribution to B2B marketing management. In addition, we require that all manuscripts published in IMM make strong theoretical contributions, offer clear rationales for all hypotheses, rely on a research methodology that is both reliable and valid, and contain meaningful discussions of their findings, significance, managerial relevance, and limitations. We expect $I M M$ reviewers to state their honest opinions, with explanations and suggestions for improvement, so that their feedback meaningfully helps authors improve their research. That is, we will insist on reviews that are objective, constructive, neutral, unbiased, and beneficial to both authors and editors, in that their detailed suggestions indicate how the authors can enhance the content and presentation of their manuscripts.

In the next step of the review process, we expect authors to address all the issues raised but not necessarily to agree with all the reviewers' comments and suggestions. Academic research should encourage debate and the exchange of information; the academic review process should do the same. As long as authors work to enhance the rigor and quality of their 
contributions, we encourage such interactions. In this context, we aim to be true 'editors,' rather than 'review collectors,' so we will adjudicate as necessary any significant disagreements across reviews or between reviewers and authors; the final publication decision is ours. Because reviewers' opinions sometimes vary, we expect reviewers to offer clear, well-substantiated comments. However, those comments also should focus on the substance of the manuscript contents and their review, rather than their beliefs about the most appropriate publication decision. That decision rests solely with the editors and may, in some cases, differ from the reviewers' recommendations.

Next, we plan to review the composition of the Editorial Review Board to ensure a sufficient range of expertise, concomitant with the reputation of $I M M$. This editorial offers us a wonderful opportunity to thank every reviewer who has contributed to this reputation in the past and made the publication of the journal possible. To remain on the Editorial Review Board, we will followed the 'rule' that Peter LaPlaca introduced, namely that reviewers will need to submit three 'successful' reviews before they are listed in IMM and on the journal's website as members of the Editorial Review Board; reviewers then must be prepared to complete at least three new 'successful' reviews (including subsequent revisions) each year to remain on the list... if there is a need for this. Authors submitting their own manuscripts to $I M M$ also should expect to assist in the journal's review process in the future; colleagues cannot expect others to provide feedback on their own manuscripts but fail to provide similar service to others!

\section{Topic Editors}

We continue to investigate whether introducing Topic Editors would provide significant benefits. At IMM, each Topic Editor would be a leading scholar in a substantive area who could act as a 'sounding board' and expert in the field. Rather than reviewing every manuscript related to his area, the Topic Editor would help identify suitable reviewers and act as an authoritative expert who could help provide more in-depth assessments. These roles continue to be a source of consideration and debate, not just for IMM but in accordance with the constantly evolving agenda for marketing. At this time, Jens Geersbro serves as the special issue editor; and Christian Felzensztein and Ghasem Zefarian serve as associate editors. 


\section{Special Issues}

We will continue with special issues. With this drive, we seek to continue IMM's tradition of compelling special issues that raise debate and attract widespread citations. Typically, a hot, high-potential topic is singled out, and with the permission of the special issue editor, guest editors solicit a collection of research articles on the topic, selecting the best of them for publication in the special issue. Thus, special issues serve two functions: alert the journal's readers to the growing importance of a topic while summarizing what is known so far about it, and present the newest research, often authored by a mix of senior academics and the best and brightest of the most recent generation of assistant professors. A special issue ideally becomes the go-to issue for researchers interested in that topic for many years to come.

Only scholars with successful publication records in $I M M$ or other high-ranking journals relevant to the focus of $I M M$ should consider submitting their proposals for careful and respectful consideration by the special issue editor. Scholars proposing a special issue will need prepare a proposal. To get an idea of how to prepare a proposal, please refer to past proposals posted on the journal's homepage.

\section{Target Articles, Position Articles, Letters to the Editor, and Book Reviews}

Among our content-related adjustments, we plan to (re-)introduce the innovative concept of 'target articles' to IMM. Each target article will be one we have selected as likely to stimulate debate. With the selection of such a target article, we will solicit two to three short commentaries and responses, and then give the authors of the target article a chance to respond in turn. The article and its associated rejoinders will appear together in the same issue. This (re-)introduction reflects our goal of advancing knowledge through debate and differences of opinion. The selection constitutes an honor for the target article authors, as well as a clear signal of the esteem of those who agree to submit comments.

We also seek to introduce the concept of 'position articles' to IMM. The idea is to have prominent academics write a brief one- or two-page position article to stimulate debate. For example, is social B2B marketing management effective or is it simply 'e-wash' that does not help anyone at all? Position articles would require a theoretical background and basis with a brief (e.g., five to 10) reference list, but would still allow academics to put their heads above the parapet and discuss things that currently are left unsaid.

Furthermore, we introduce the idea of brief 'letters to the editor' with comments from readers to see if there was a consensus one way or the other. 
Finally, from time to time, we will bring reviews of books pertaining to the interest of IMM readers.

\section{Articles from Practitioners}

$I M M$ is proud of its position as the leading journal for practitioners in the field of industrial and B2B marketing management. We will seek to solicit—from time to time-smaller pieces from leading practitioners.

\section{Outstanding Article Award}

In 2005, Peter LaPlaca initiated the Outstanding Article award to recognize the best article of the past year, as judged by the total number of downloads. A glance at the research topics represented by these articles is instructive in that it suggests which B2B marketing management topics are currently hot and inspiring further research. Overall, the topics in the outstanding articles are among those subjects that have received notable research attention. Any article that has been downloaded enough times to be selected as an award winner potentially is a source of inspiration for new research directions. In future years, we will award not only the most downloaded article, but also the second and third most downloaded articles (runner-ups).

\section{IMM Summit}

$I M M$ 's global reach is evidenced by the fact that international scholars and practitioners from North America, Europe, Australia/New Zealand, Asia, and other regions of the globe share their latest findings for improving effectiveness and efficiency of industrial and B2B markets. This comprehensive approach has helped to keep readers abreast of the timeliest research and practice necessary for better marketing decisions and strategy in global industrial and business-to-business markets.

Together with Elsevier, we wish to develop IMM's role in the academic debate by launching a new initiative, namely the inaugural $I M M$ summit. The aim of the summit is to offer a platform for debating (as opposed to writing and reading) current theory and practice challenges and their solutions. We wish to establish an interactive format enabling academia to develop and discuss thought leadership thereby developing solutions for society.

The summit will be informal in its form, with an emphasis on discussion on how to improve manuscripts so that they will be ready for inclusion in a special issue of IMM. After the summit, selected manuscripts will be double-blind reviewed along the lines of the 
journal's reviewing policy; and manuscripts that have passed this double-blind reviewing process will be published in a special issue of IMM.

The first summit will take place 24-26 January 2018 at Copenhagen Business School. This summit focusses on recent advances in theory and practice within global industrial and B2B marketing management. We hope to see the summits as an annual event.

\section{Closing Comments}

As this editorial should have made clear, we are sincerely excited about working with our colleagues and enthusiastic about moving IMM forward as a key channel for disseminating new, insightful marketing knowledge worldwide. We encourage collaborative efforts among our authors, the Editorial Review Board, the Advisory Board, Associate Editors, Topic Editors, and the Editor-in-Chief, initiating productive exchanges that ultimately will help us all understand the wide and exciting domain of industrial and B2B marketing management more clearly. Most important, we hope you will keep considering IMM a high-quality destination for your best work.

Adam Lindgreen, Ph.D.

Co-Editor-in-Chief

Copenhagen Business School, Denmark \&

University of Pretoria's Gordon Institute of Business Science

adli.marktg@cbs.dk

C. Anthony Di Benedetto, Ph.D.

Co-Editor-in-Chief

Fox School of Business, Temple University, USA

tonyd@temple.edu 